\title{
Comparison of large-scale energy storage technologies
}

\author{
Florian Klumpp Dr.-Ing. \\ Senior Consultant and Project Manager, Department of Renewable \\ Energies \& Environment, FICHTNER GmbH \& Co. KG, Stuttgart, Germany \\ (corresponding author: florian.klumpp@fichtner.de)
}

In this paper, technologies are analysed that exhibit potential for mechanical and chemical energy storage on a grid scale. Those considered here are pumped storage hydropower plants, compressed air energy storage and hydrogen storage facilities. These are assessed and compared under economic criteria to answer the question of which technology is to be favoured. For this purpose, the levelised electricity cost for various dispatch scenarios - short-, medium- and long-term storage - are calculated for the present and for 2030. Fundamental indicators considered are their respective efficiencies, capital expenditure and operational expenditure, and technical service lives. From an economic point of view, today pumped hydro is the most cost-efficient short- and medium-term storage technology, closely followed by compressed air energy storage. In the future, too, there will be no fundamental change in this result, even with optimistic assumptions for the development of hydrogen storage. However, hydrogen storage is becoming more competitive and represents the most economic option in the future for long-term energy storage.

\begin{tabular}{ll}
\multicolumn{2}{l}{ Notation } \\
$C$ & capacity/energy specific \\
dis & discharged \\
$i$ & discount rate \\
$n$ & technical lifetime \\
$P$ & rating/power specific \\
$t$ & year \\
tot & total \\
$W$ & energy
\end{tabular}

\section{Introduction}

\subsection{Status of scientific and technical knowledge}

This paper summarises some key results of a 1-year research project being conducted for the State Ministry of the Environment and the State Ministry of Economics in Lower Saxony, Germany (Fichtner, 2014). The paper deals with largescale energy storage and the associated cost of storing energy. On the basis of the ultimate goal of a secure, environmentally friendly and cost-efficient electricity supply, this question is of great relevance when comparing different storage technologies.

Many national and international papers analyse storage technologies with regard to their technical elements, such as efficiency and typical capacity, and their economic data - for example, capital expenditure (Capex), operational expenditures (Opex) and so on (CLCF, 2013; Crotogino, 2010; Rastler et al., 2012).
This research paper combines all relevant parameters such as Capex, Opex, price of charging electricity, discount rate, technical lifetime, efficiency and so on in a storage modelling tool to calculate the average discounted electricity storage cost, termed as the levelised electricity cost (LEC). The LEC approach is typically applied to determine the 'true cost of generating electricity' for generation technologies (Konstantin, 2013; Kost et al., 2013; Wissel et al., 2008, 2010). This paper transfers and applies this methodology to storage technologies.

One important new aspect of this paper is the differentiation of diverse dispatch scenarios for storage technologies into short-, medium- and long-term storage (STS, MTS, LTS). As these dispatch scenarios and the respective technical plant design - that is, the ratio of capacity in megawatt hours (MWh) and installed power in megawatts (MW) - differ fundamentally, it is important to match properly the technical setting of the storage technologies and their cost structure. In many research papers, no differentiation is made between power-dependent $(€ / \mathrm{kW})$ and energy-dependent Capex $(€ / \mathrm{kWh})$. This differentiation is of fundamental importance for correct modelling of the storage systems and their initial Capex in diverse dispatch scenarios.

As will be shown, the dispatch scenario exerts a decisive influence on the technical setting of the respective storage facility, the economic input parameters and ultimately their average discounted electricity storage cost. This effect, 
together with a sensitivity analysis and an outlook up to 2030 is presented.

\subsection{Background}

In the context of the German government's energy policy reorientation (Energiewende), in future a significant share of electricity will be generated from wind and solar energy, which is available only intermittently. To ensure reliable energy supply, alongside accelerated expansion of the power grid and placing standby power plants in readiness, energy storage will play a key role.

\subsection{Points at issue}

The intention of this paper is to answer the question of which utility-scale energy storage technology is to be favoured now and in 2030. For the calculation, all substantive technical and economic parameters are to be taken into consideration.

\section{Storage systems coming into consideration}

For utility-scale storage facilities, various technologies are available, including some that have already been applied on a large scale for decades - for example, pumped hydro ( $\mathrm{PH})$ and others that are in their first stages of large-scale application, like hydrogen $\left(\mathrm{H}_{2}\right)$ storage. This paper addresses three energy storage technologies: $\mathrm{PH}$, compressed air storage (CAES) and hydrogen storage (Figure 1). These technologies are among the most important grid-scale storage options being intensively discussed today. However, other technologies are being proposed, such as various battery technologies and liquid air, which could be assessed in further work.

First, the basic operating principle of each storage technology is briefly outlined. For more detailed background information, reference is made to the extensive technical literature on this topic (dena, 2010; EFZN, 2013; Hartmann et al., 2012; RWE Power Aktiengesellschaft, 2010).

Within the framework of this comparison, each storage technology is depicted against a reference storage system, with a fixed plant configuration - for example, electrolysis with a $300 \mathrm{MW}$ proton exchange membrane (PEM) electrolyser and so on. This approach means that it is possible to analyse in

\section{Considered storage technologies}
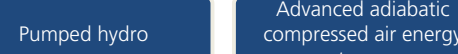

Hydrogen storag

Figure 1. Storage systems coming into consideration detail an actual, clearly defined system as part of further considerations, including among others, an LEC calculation. The indicative values of the reference storage systems are tabulated in Section 3.

\subsection{Pumped storage hydropower plant}

\subsubsection{General}

Typically, a pumped storage hydropower plant consists of upper and lower basins, with these connected by way of an underground chamber consisting of a turbine, pump, generator and a transformer, as well as penstock and tailrace tunnels. The storage capacity of such a plant depends on the basin sizes as well as the mean elevation difference between the upper and lower basins. For economic operation, usually $200 \mathrm{~m}$ is assumed as the minimum head. Thanks to their short start-up time of around 1-2 min up to full load operation, $\mathrm{PH}$ can be used for providing both balancing power to maintain grid stability and for energy storage.

\subsubsection{Operating principle}

At times of high or excess power availability, the motor-generator drives the shaft to operate the pump. This pumps the water from the lower basin through the penstock into the upper basin, where it is stored, so electrical energy is converted into potential energy by virtue of the elevation difference (Figure 2).

If the energy store - the upper basin - is to be discharged to generate electrical power, the pumped storage hydropower plant is reversed. Water from the upper basin is discharged through the penstock to operate the turbine and thus the motor-generator, thus converting the potential energy back into electrical energy. The electricity is supplied to the power grid by way of the transformer.

Some of the input energy is lost due to the conversion processes when water is transferred into and discharged from the upper basin. Nevertheless, these power plants with an efficiency of $\sim 80 \%$ (dena, 2010) count among the utility-scale energy storage technologies with the highest efficiency.

\subsubsection{State of the art - commercial availability of the technology}

Since its introduction in the UK in the early 1960s (Dinorwig, Wales, and Awe, Scotland), pumped storage hydro is the most widely applied form of electricity storage technology. This is a mature technology that is commercially available. New storage facilities require appropriate topography and construction of large reservoirs, especially if they are designed as long-term energy stores, which pose consenting and environmental constraints. 


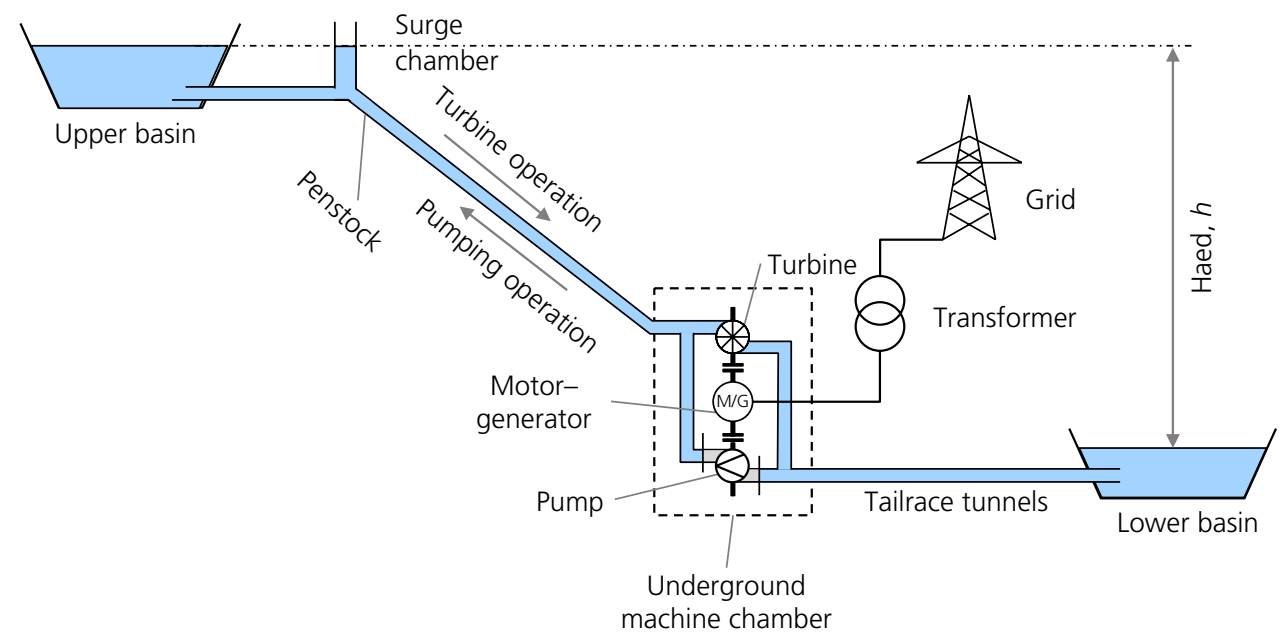

Figure 2. Operating principle of a pumped storage hydropower plant (modified from Schapitz (2014))

\subsection{Compressed air energy storage}

\subsubsection{General}

A CAES facility consists of the following components: machine house with air ingestion, compressor with generator and turbine, and underground cavern or caverns. An adiabatic compressed air storage facility is equipped additionally with a thermal store (Figure 3).

\subsubsection{Operating principle}

At times of high or excess power availability - for example, due to the fluctuating infeed rate of renewable energies ambient air is drawn in, pressurised by a compressor, cooled in a heat-transfer system and stored in an underground cavern in the form of compressed air at between 40 and 70 bar (4-7 MPa) (EFZN, 2013). This process may be termed charging of the energy store. If the store is to be discharged, the stored compressed air is directed to the (air) turbine, which powers the generator to produce electricity.

For compressed air storage, a distinction is made between adiabatic compressed air storage, abbreviated to AA-CAES (advanced adiabatic CAES) and diabatic systems, or CAES. When air is compressed, this generates heat that in a diabatic system is released to the surroundings and so is lost. When the air is discharged, its pressure is relieved and, due to the JouleThompson effect, it cools down and external heat must be added, usually by firing natural gas, so that there will be no icing up of the air turbine as it is expanded further. In contrast, in an adiabatic system, a thermal store is integrated into the system, which absorbs the generated heat, stores it and subsequently releases it to heat up the outflowing air (Figures 4 and 5).

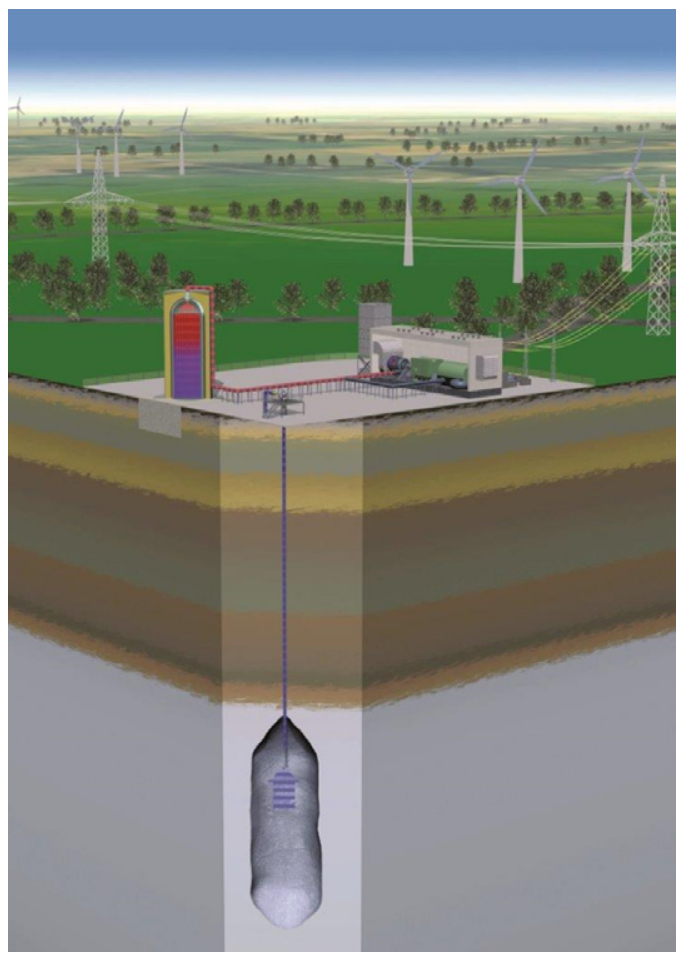

Figure 3. Principle of operation of a facility for adiabatic CAES for electricity supply (modified from RWE (2010))

\subsubsection{State of the art - commercial availability of the technology}

Compressed air storage facilities are an alternative to pumped storage hydropower plants even if only small numbers of 


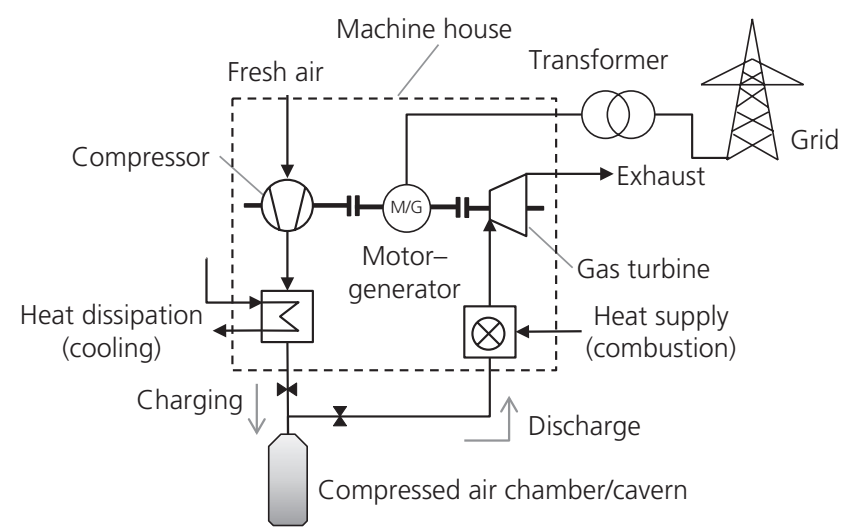

Figure 4. Principle of operation of a diabatic CAES facility (modified from Schapitz (2014))

utility-scale plants have been constructed. At present, the only projects that have been implemented are the Huntorf CAES plant in Lower Saxony, Germany, and the McIntosh facility in Alabama, USA. It is to be noted that these are diabatic compressed air storage facilities. Adiabatic compressed air storage is a technology that is not yet commercially available. Particular technical challenges are presented by compression at high temperature and realisation of the thermal store. From the author's viewpoint, these challenges can be overcome. Provision of large caverns appropriate for the application of AA-CAES for LTS is generally technically feasible, although it must be ensured that relevant safety requirements are complied with.

\subsection{Hydrogen storage}

\subsubsection{General}

The basis of all three storage paths depicted in the following is hydrogen generation by means of electrolysis. In this process, water is split into its constituents, oxygen and hydrogen. Taking as a starting point the gaseous state of hydrogen after electrolysis, there are numerous possibilities for storing hydrogen.

\subsubsection{Operating principle}

When storing hydrogen, this study throws light on three storage paths. In each of these, the generated hydrogen is reconverted into electricity - that is, power-to-power. These three paths are as follows.

- Path 1: storage of hydrogen in caverns.

- Path 2: storage by direct infeed of hydrogen into the natural gas grid (for limits see DVGW (2013)).

- Path 3: storage by methanation of hydrogen to synthetic methane, followed by its infeed into the natural gas grid.

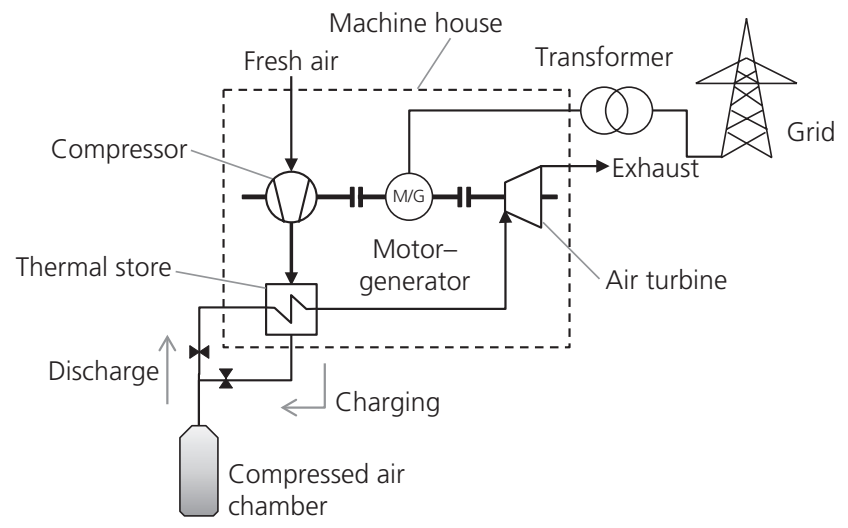

Figure 5. Principle of operation of an adiabatic CAES facility (modified from Schapitz (2014))

In all three paths, fuel cell (FC) technology has been selected for reconversion into electricity. For paths 2 and 3, in particular, reconversion in a conventional combined cycle power plant (CCPP) is conceivable. The advantage of the selected process, though, is that the three paths can be better compared. Favouring reconversion with CCPP are its higher efficiency, commercial availability of high power ratings, low Capex and long service life of combined cycle power plants compared with FCs (Figure 6).

\subsubsection{State of the art - commercial availability of the technology}

Components for hydrogen storage - electrolyser, FC and so on are currently designed for small-scale applications in the lower single-digit MW range, but they are commercially available for this purpose. To implement on a plant scale of $300 \mathrm{MW}$, as considered for this study, several small plants/units would have to be connected together. On the basis of the underlying modular design, this is technically feasible. This scaling up is confirmed by original equipment manufacturers as well as in international publications (CLCF, 2013; Lehner et al., 2014). Provision of appropriate caverns, in particular for LTS, is feasible if suitable salt formations are available. Such salt formations for caverns for hydrogen and CAES are available in many European countries (Crotogino, 2011; Donadei and Zander-Schiebenhöfer, 2015; Donadei et al., 2013; Simona et al., 2015). For detailed maps of potential salt caverns in Northern Germany, see Fichtner (2014). Potential competition between natural gas storage and storage for hydrogen or compressed air needs to be taken into consideration when evaluating the overall potential.

\section{Methodology and analytical approach}

3.1 LEC

Prioritising the storage systems is a key objective of this paper. For an economic comparison of the technologies, the average 


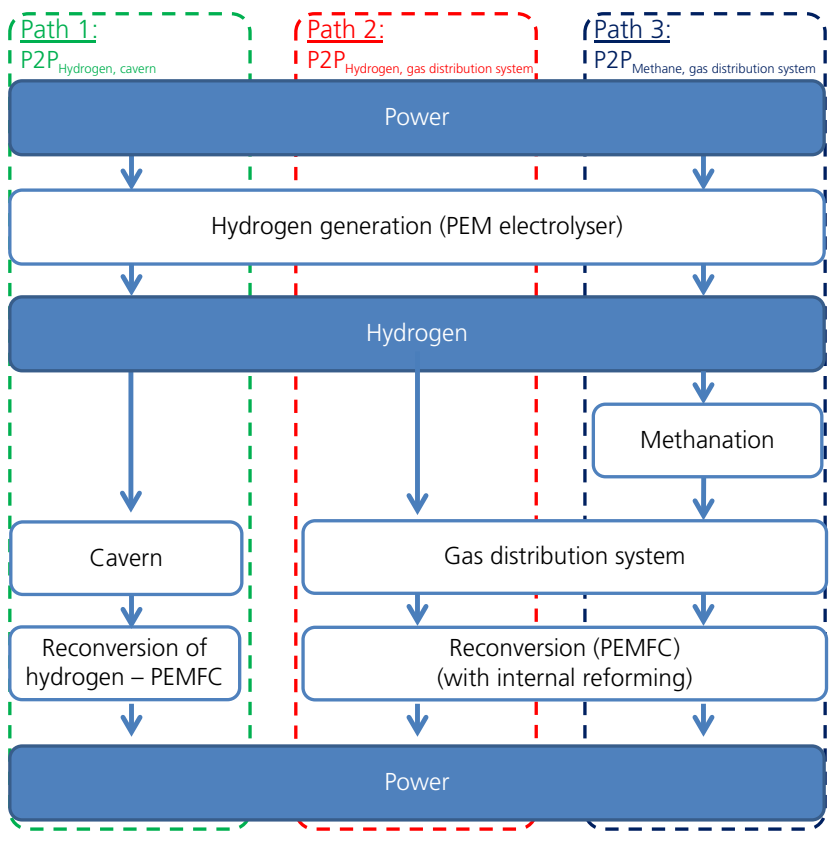

Figure 6. Potential hydrogen storage paths considered in this study. PEM, polymer electrolyte membrane; PEMFC, polymer electrolyte membrane fuel cell

discounted electricity cost, termed as the LEC, is calculated. When applied to energy storage systems, it corresponds to the average discounted costs of energy storage. According to Konstantin (2013), it may be derived by applying the net present value method that has wide application in practice. For a detailed description of the theory, reference is made to a range of publications, for example, Konstantin (2013), Kost et al. (2013), Wissel et al. (2008) and Wissel et al. (2010). Equation 1 can, but does not necessarily have to, be simplified and transformed to Equation 2 if annual Opex $\left(\mathrm{Opex}_{t}\right)$ and annual discharged energy $\left(W_{t}\right)$ are constant.

Key inputs for calculating LEC are Capex and the discounted annual costs for operation and maintenance, Opex. The latter is made up, first, of costs for servicing and maintaining the installations and, second, the costs of the electricity consumed for charging the storage facility. Taken as basic assumptions for calculating LEC are a charging electricity price of $€ 50 / \mathrm{MWh}$ and a discount rate of $5 \%$. The service lives of the technologies differ significantly. This is accounted for in the calculation by the factor ' $n$ ' representing the technical lifetime of a specific technology in years.

1. $\mathrm{LEC}=\frac{\text { Capex }_{0}+\sum_{t=1}^{n}\left(\mathrm{Opex}_{\mathrm{tot}, t} /(1+i)^{t}\right)}{\sum_{t=1}^{n}\left(W_{\mathrm{dis}, t} /(1+i)^{t}\right)}$

\begin{tabular}{lcc}
$\begin{array}{l}\text { Dispatch } \\
\text { scenarios }\end{array}$ & $\begin{array}{c}\text { Energy recovery period } \\
\text { (capacity:power ratio): } h\end{array}$ & Cycles per day \\
\hline STS & 1 & 7 \\
MTS & 7 & 1 \\
LTS & 200 & 0.033
\end{tabular}

Table 1. Definition of dispatch scenarios for energy stores

2.

$$
\begin{aligned}
\mathrm{LEC} & =\frac{\text { Capex }_{0}+\text { Opex }_{\mathrm{tot}, t} \cdot\left(q^{n}-1 / q^{n} \cdot(q-1)\right)}{W_{\mathrm{dis}, t}\left(q^{n}-1 / q^{n} \cdot(q-1)\right)}, \\
q & =1+\frac{i}{100}
\end{aligned}
$$

where LEC is the levelised electricity cost (€/MWh); Capex is the capital expenditure $(€)$; Opex is the operational expenditure (€); $W$ is the energy (MWh); $i$ is the discount rate (\%); $t$ is the year (dimensionless); $n$ is the technical lifetime (dimensionless); dis is the discharged; and tot is the total (in year $t$ ).

\subsection{Dispatch scenarios}

For this study, the deployment of storage systems is investigated on the basis of the following dispatch scenarios: STS, MTS and LTS. These are defined in Table 1. On the basis of the selected energy recovery period and number of cycles, for all dispatch scenarios there results around $7 \mathrm{~h} / \mathrm{d}$ of full-load operation during which the storage facility discharges energy. Referred to a year, this amounts to around $2500 \mathrm{~h}$ of full-load operation, corresponding to just about $30 \%$ of the year $(8760 \mathrm{~h})$.

For very low total efficiencies (e.g. $21 \%$ for hydrogen storage facilities), these operation regimes require either a higher charging capacity, a reduction of cycles per day or a (partly) simultaneous charging (electrolysis) and discharging (reconversion with FCs) operation. This is possible due to the technical decoupling of electrolysis and reconversion. However, this is more of a hypothetical option.

\subsection{Differentiation between energy- and power-specific investments}

Usually, in the literature, for various storage technologies, bandwidths for energy- and power-specific Capex are quoted in $€ / \mathrm{kWh}$ and $€ / \mathrm{kW}$, respectively. These bandwidths are determined for typical ratios of volumetric storage capacity to power output referred to the capacity and power of the entire storage system.

To model properly the dispatch scenarios defined in this paper STS, MTS and LTS - costs must be decoupled and calculated separately for the energy-dependent and power-dependent subsystems of the storage facility. For this purpose, the costs for each 
subsystem are determined. Thus, for example, the costs of the required basins or caverns for the differing applications for STS, MTS, or LTS are calculated separately (Table 2).

These costs are referred to the energy that can be stored and are quoted in $€ / \mathrm{kWh}$. For power-specific Capex, specific values in $€ / \mathrm{kW}$ are selected from the technical literature as well as on the basis of empirical values known from previous projects. The respective indicator values of the storage systems considered are shown in Table 3. The total Capex of a storage system (Figure 7) is the sum of its energy- and power-specific Capex.

\subsection{Summary of key indicative values for storage technologies}

As described, each storage technology is defined against a reference storage system, with a fixed plant configuration - for example, electrolysis with a $300 \mathrm{MW}$ PEM electrolyser and so on. The aim is to calculate the technologies' LEC so that the storage systems can be compared. Compiled in the following are the technical and economic indicative values of the reference storage systems.

\subsubsection{Technical indicative values of the reference storage systems}

Fixing of power ratings. The referenced $\mathrm{PH}$ project (336 MW) was designed by way of example as a reference storage system based on the specifics of potential sites in Lower Saxony (for details see Fichtner (2014)). The AA-CAES of $90 \mathrm{MW}$ is based on the Adiabatic Compressed Air Energy Storage for Electricity Supply (ADELE) research project. The rating of the hydrogen storage of $300 \mathrm{MW}$ has been freely selected.

A key indicative value of storage systems is their overall efficiency as depicted in Figure 8.

\subsubsection{Economic indicative values of the reference storage systems}

In paths 2 and 3, hydrogen and synthetic methane, respectively, are fed into the existing natural gas grid. For hydrogen no adaptation of the existing natural gas grid is necessary up to 2 vol\% of hydrogen (DIN, 2008; DVGW, 2013; Fichtner, 2014). The feed-in of hydrogen into the existing gas grid is already being demonstrated today at multiple sites, such as Falkenhagen (E.ON SE, 2014). For synthetic methane there is no technical limitation except for the transportation capacity of the natural gas pipelines in regard to the existing natural gas grid; natural gas is replaced by synthetic methane. The cost of connecting the storage system, comprising electrolysis and methanisation, to the existing gas grid is considered in the Capex of the respective storage system. No additional costs accrue in the existing natural gas grid to absorb and 


\begin{tabular}{|c|c|c|c|c|c|}
\hline Economic indicative values & $\mathrm{PH}$ & AA-CAES & $\begin{array}{c}\text { Hydrogen } \\
\text { cavern }\end{array}$ & $\begin{array}{c}\text { Hydrogen } \\
\text { gas grid }\end{array}$ & $\begin{array}{l}\text { Methane } \\
\text { gas grid }\end{array}$ \\
\hline Power-specific Capex ${ }^{\mathrm{a}, \mathrm{b}}: € / \mathrm{kW}$ & 487 & 910 & 2500 & 2600 & 4255 \\
\hline Energy-specific Capex (STS/MTS/LTS) ${ }^{\text {c,d: }} € / k W h$ & $115 / 102 / 57$ & $204 / 34 / 21$ & $36 / 6 / 0 \cdot 3$ & 0 & 0 \\
\hline Percentage (of Capex) to calculate fixed Opexe: \%/a & $0 \cdot 8 / 0 \cdot 5 / 0 \cdot 3$ & $1 \cdot 8$ & $3 \cdot 0$ & $3 \cdot 0$ & $3 \cdot 0$ \\
\hline
\end{tabular}

Source of economic indicative values: references given below and own calculations based on projects planned and implemented by Fichtner

${ }^{a}$ Source: dena (2013)

bource: Mahnke and Mühlenhof (2012)

'Source: Hartmann et al. (2012)

dSource: Genoese (2013)

eSource: Fichtner (2014)

Table 3. Economic indicative values of the reference storage

systems

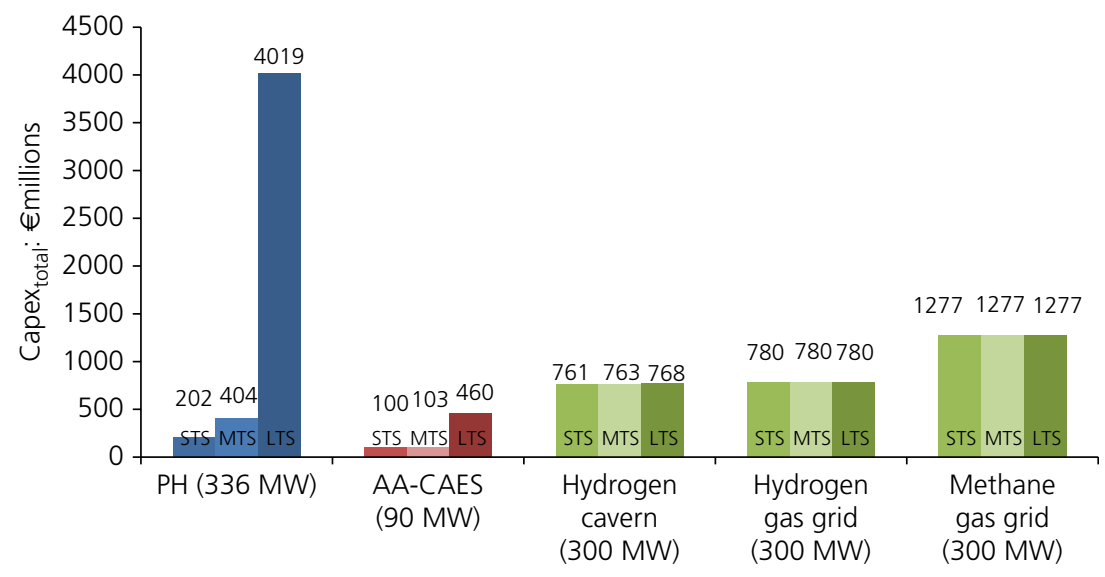

Figure 7. Total initial Capexs of the investigated storage systems

(excluding reinvestment costs for hydrogen storage)

to store hydrogen or synthetic methane. For this reason, the energy-specific Capex for hydrogen storage in paths 2 and 3 , with hydrogen and synthetic methane, respectively, transferred to storage in the natural gas grid, is set to $€ 0 / \mathrm{kWh}$.

The total Capex of the investigated storage systems is shown in Figure 7 for various dispatch scenarios. As already noted, total Capex is made up of power- and energy-specific Capex. Energy-specific Capex depends greatly on the selected dispatch scenario - STS, MTS, LTS - and the reservoir or cavern volumetric capacities that have to be implemented as a consequence.

When comparing total Capex figures, it is important to bear in mind that the storage system options have differing power ratings.
- $\mathrm{PH}, 336 \mathrm{MW}$.

- AA-CAES, $90 \mathrm{MW}$

- Hydrogen storage, $300 \mathrm{MW}$.

Owing to these differing power ratings, the comparability of these technologies is limited. Nevertheless, the graph clearly shows the absolute Capex amounts that are to be expected for the investigated reference storage plants (Figure 7).

The units of the vertical axis in Figure 7 are total Capex $\left(\right.$ Capex $\left._{\text {total }}\right)$, in million euros as needed initially to construct the respective storage system. As discussed, total Capex depends greatly on the selected dispatch scenario - STS, MTS, LTS. It can be seen that, for constructing pumped storage hydropower plants for long-term dispatch scenarios, a huge total Capex would be required. The major driver is Capex for 


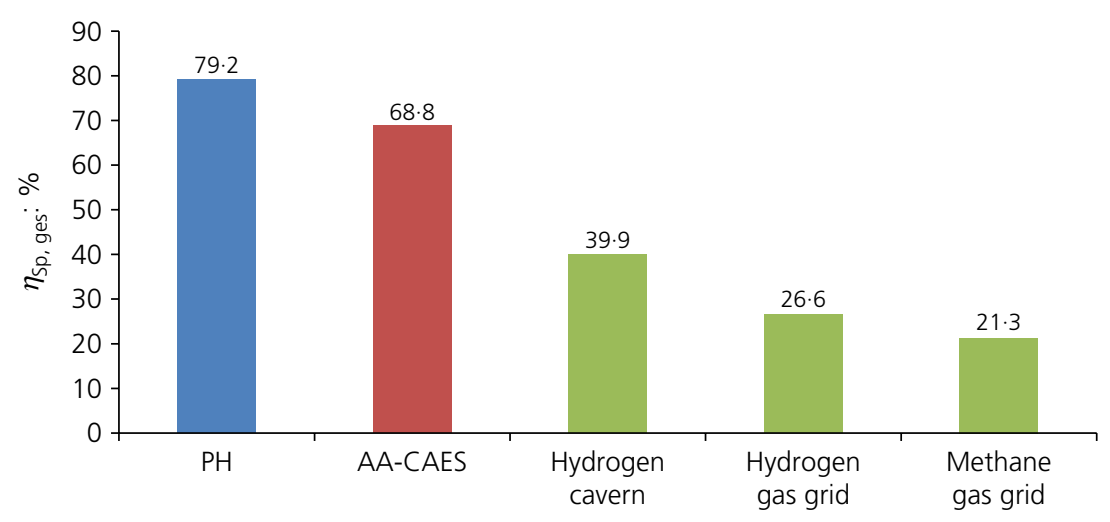

Figure 8. Overall efficiencies of the investigated storage systems

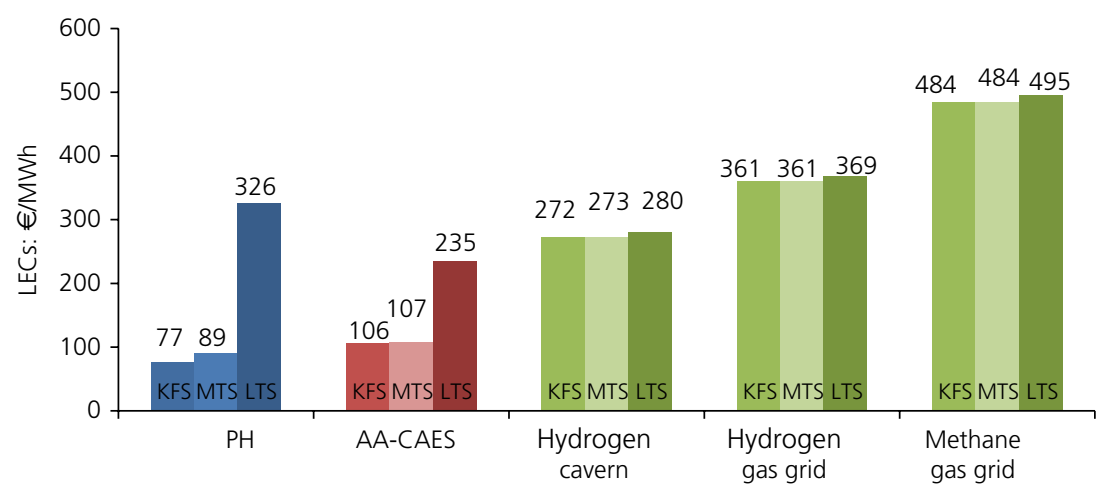

Figure 9. LECS of storage systems for differing dispatch scenarios:

STS, MTS and LTS

the reservoirs. As discussed, the construction of large reservoirs for PH (especially if designed as long-term energy stores) poses not only consenting and environmental constraints but is also very costly with regard to initial Capex. Of all storage options, adiabatic compressed air storage requires the lowest specific Capex, while this is highest for hydrogen storage. The only exception to this, as already noted, is PH designed for LTS. In the case of hydrogen storage, it is striking that Capex remains virtually constant despite differing dispatch scenarios.

\section{Prioritising the storage technologies}

\subsection{Present situation}

In the following, the investigated storage systems are prioritised on the basis of their economic performance. For this purpose, the LECs for the storage technologies are compared under the differing dispatch scenarios of STS, MTS and LTS (Figure 9).
Depending on the dispatch scenario, the storage technologies exhibit differing LECs. In the short-term dispatch scenario, $\mathrm{PH}$ at $€ 77 / \mathrm{MWh}$ is the best option, closely followed by compressed air storage at $€ 106 / \mathrm{MWh}$. This is followed, after a wide margin, by hydrogen storage in the cavern (path 1) at $€ 272 / \mathrm{MWh}$, hydrogen storage in the natural gas grid (path 2) at $€ 361 / \mathrm{MWh}$ and hydrogen storage with methanation and methane storage in the natural gas grid (path 3 ) at $€ 484 / \mathrm{MWh}$. This ranking does not change for the medium-term dispatch scenario. Here too, the costs for hydrogen storage are around three to six times that of stored hydro. For long-term dispatch, however, compressed air storage advances to first place at $€ 235 / \mathrm{MWh}$, followed by hydrogen storage in the cavern at $€ 280 / \mathrm{MWh}$ and $\mathrm{PH}$ at $€ 326 / \mathrm{MWh}$.

The breakdown of costs for the various components is shown in Figure 10. From this, it is possible to derive conclusions for, among others, the sensitivity to variation of the different 

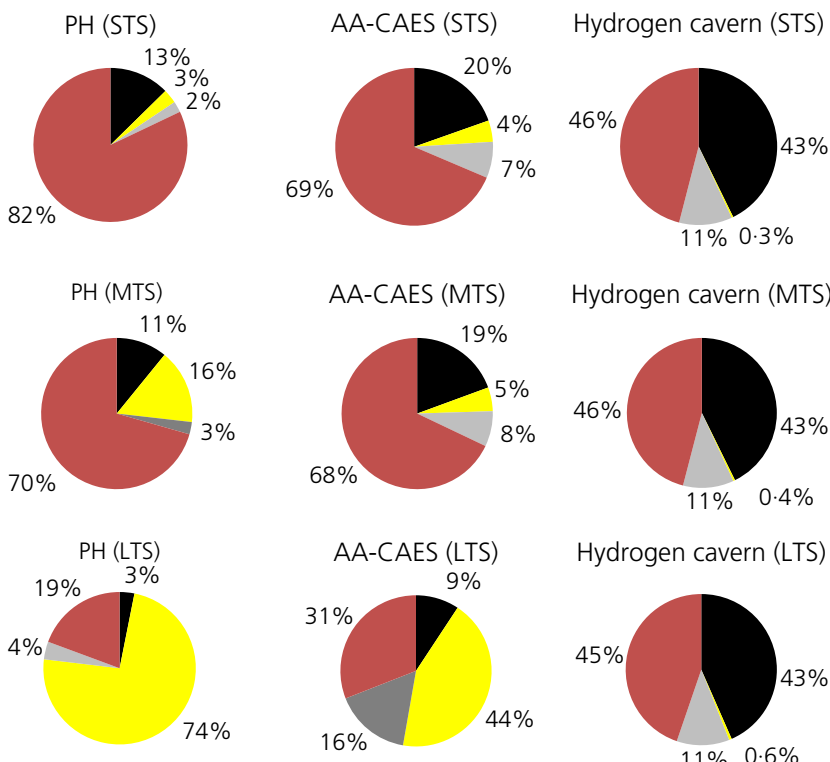

Hydrogen cavern (MTS)

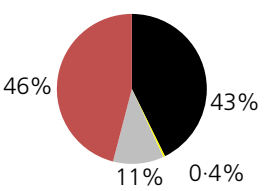

Hydrogen cavern (LTS)

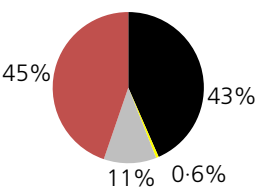

- Capexspec, P (power-spec.) Capexspec, C (energy-spec.) Opex fix $(\mathrm{O}$ and $\mathrm{M})$

Figure 10. Percentage shares in LEC of power- and energyspecific Capex and of fixed and variable Opex

parameters. Thus, for example, the small change in LEC for hydrogen storage when varying the dispatch scenario between the short, medium and long term is attributable to the low share of energy-specific Capex of from $0 \cdot 3$ to $0 \cdot 6 \%$ in the LEC.

\subsection{Sensitivity analysis - influence of various parameters on the LEC}

The sensitivity of the average, discounted costs of energy storage (LEC) of the investigated storage technologies is described in the following. STS and MTS with 1 and $7 \mathrm{~h}$ energy recovery periods, respectively, show only small differences. For this reason and in the interests of clarity, only STS and LTS facilities are investigated.

\subsection{1 $\mathrm{PH}$}

It can be seen that the efficiency of STS and MTS exerts a very great influence on the LEC: if the efficiency shifts up or down by $20 \%$, the LEC becomes $20 \%$ more favourable or more costly in step. For the LTS, in contrast, an increase in efficiency by $20 \%$ saves only around $2 \%$ of the LEC. The reason for this is the decreasing significance of variable Opex (i.e. electricity costs) on the LEC, as shown in Figure 10.

Moreover, the influence of the price of electricity for storing energy is very great, and is lessened for LTS in comparison to the other two scenarios. The opposite is true for the discount
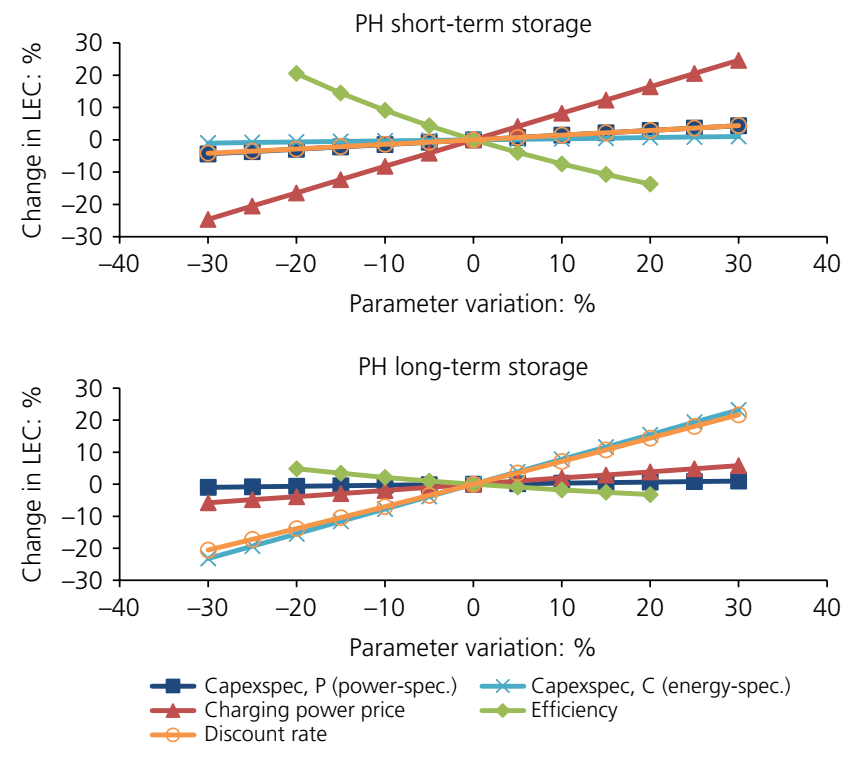

Figure 11. Sensitivity of the LEC of the reference PH system to the various dispatch scenarios

rate and energy-specific Capex. For the short-term scenario these have no or a relatively small impact. The influence increases for LTS to the extent that a change of the discount rate of $30 \%$ brings about a change in LEC of around $20 \%$ (Figure 11).

\subsubsection{Adiabatic compressed air storage (AA-CAES)}

For compressed air storage (Figure 12), the behaviour is similar to that of PH. Efficiency and the price of electricity for storing energy greatly influence STS, and this is lessened for LTS. In relative terms, however, as a maximum the change in LEC is only $19 \%$. Energy-specific Capex and discount rate gain influence for LTS, although they only bring about at the most a change of $18 \%$ for a variation of $\pm 30 \%$.

This increase or decrease in influence is attributable to the relative shares of the components as noted above. If a component, for example, energy-specific Capex, has a large share in LEC, if this is varied it has a correspondingly high impact.

\subsubsection{Hydrogen storage}

The sensitivity of hydrogen storage in the cavern (path 1) as a proxy for paths 2 and 3 is shown in Figure 13. A noticeable feature for hydrogen storage is that sensitivities are only minimal, irrespective of the dispatch scenario.

This is also attributable to the slight changes of component shares in the LEC. In contrast to PH and AA-CAES, powerspecific Capex exerts a consistently high influence for all 

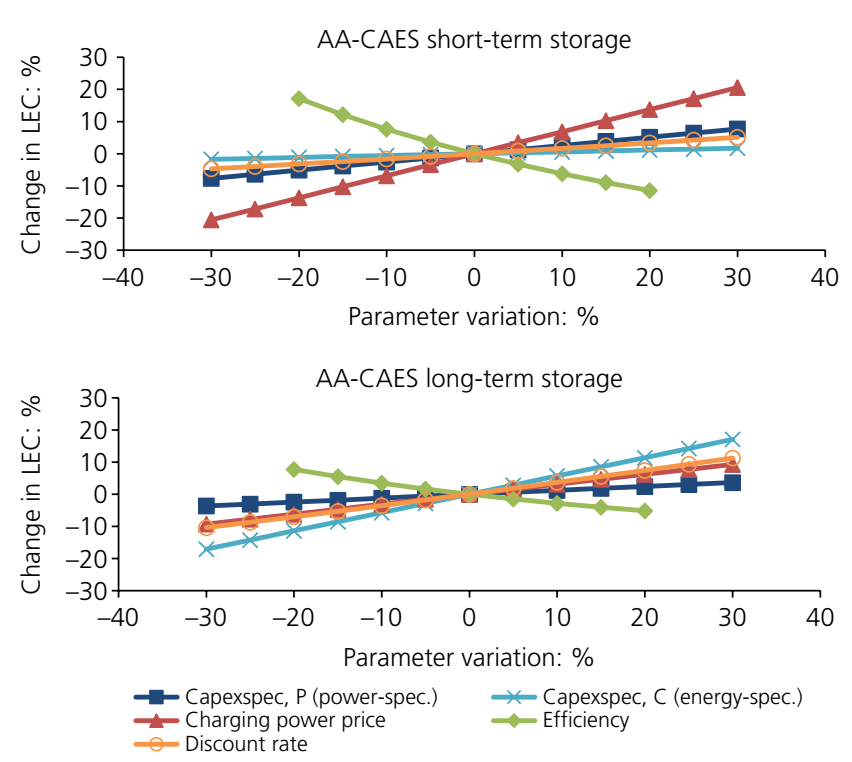

Figure 12. Sensitivity of the LEC of the reference compressed air storage system to various dispatch scenarios
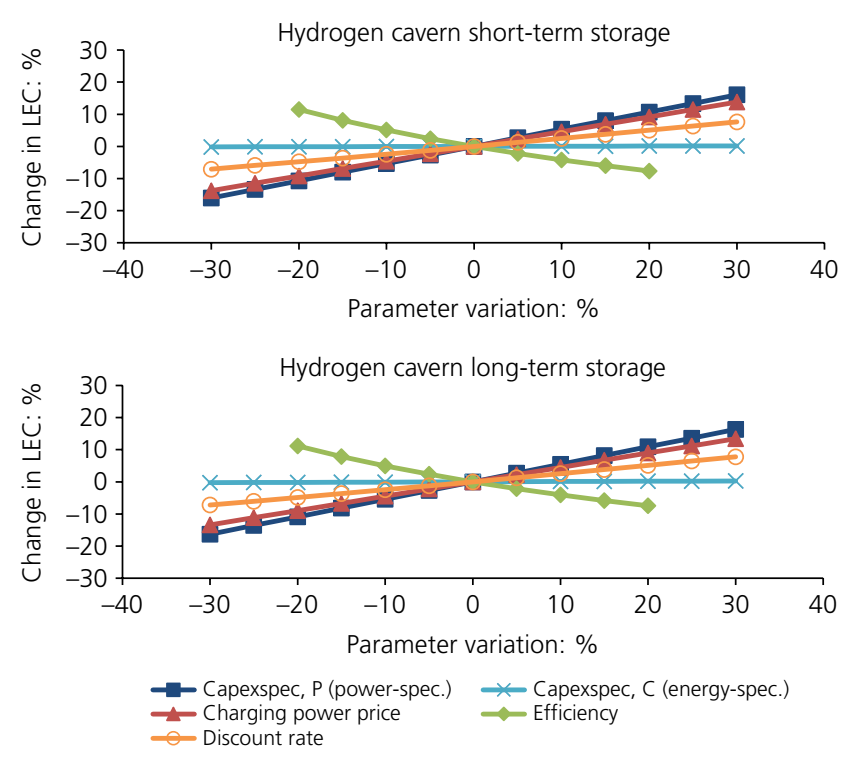

Figure 13. Sensitivity of the LEC of the reference hydrogen storage system to various dispatch scenarios

dispatch scenarios, while energy-specific Capex has no such consistent influence.

\subsection{Prospects for 2030}

To assess the developments anticipated for the future, alongside the present situation, the prospects for 2030 are also investigated for the German context. For this purpose, potential (technical) advancements are considered, as these may be expected to bring about shifts in the ranking of the storage systems and their storage costs. With the ongoing research being undertaken in several countries, it can reasonably be expected that significant improvements in new technologies will lead to a reduction in their future Capex requirements through lower production and construction costs.

- For the already established technology of PH systems, due to their technological maturity and project experience, to be on the conservative side it may be assumed that their cost reduction potential has already been exhausted.

- For the adiabatic compressed air store, for Capex a reduction of around $20 \%$ is assumed because when this technology is commercialised further cost reductions would appear to be possible.

- For hydrogen storage, the in part optimistic assumptions regarding technical development have intentionally been taken into account (for details, see Table 4). The aim is to show whether and, if so, the extent to which this would (even) change the ranking.

Proponents of hydrogen storage technology assume that possible future electricity prices quoted on the exchange will be favourable. In line with this argument, a relatively low electricity exchange price of $€ 20 / \mathrm{MWh}$ is assumed for the future scenario. This favours technologies with a low efficiency - that is, hydrogen storage. Table 4 details the values assumed for reference storage systems of the present and for 2030 .

The development of the LECs from today to 2030 is shown in Figures 14-16. Shown are the LECs calculated for the present day (figure above the columns) and the costs estimated for 2030 (figure below the columns). The bars show the bandwidths of the LECs if the anticipated future developments and technical improvements regarding higher efficiency, less costs and so on are less favourable than assumed.

STS. For short-term deployment of storage systems, up to 2030 there are reductions in LEC of around $50 \%$ for $\mathrm{PH}$, $45 \%$ for compressed air storage and $70 \%$ for hydrogen storage. The principal reason for the LEC reduction for $\mathrm{PH}$ is the low price of $€ 20 / \mathrm{MWh}$ assumed for this technology. There is no change in the ranking of the storage systems on the basis of their LECs. In 2030, too, in terms of LEC, PH is the most favourable storage technology for short-term dispatch.

MTS. For medium-term deployment of storage systems, there are reductions in LEC of around $40 \%$ for $\mathrm{PH}, 45 \%$ for 


\begin{tabular}{llll}
\hline PH & Overall efficiency & $79 \cdot 2 \%$ & Unchanged \\
& Power-specific Capex & $€ 487 / \mathrm{kW}$ & Unchanged \\
Anchanged & $€ 728 / \mathrm{kW}(-20 \%)$ \\
Hydrogen cavern (path 1) & Overall efficiency & $68 \cdot 8 \%$ & $62 \cdot 3 \%(+56 \%)$ \\
& Power-specific Capex & $€ 910 / \mathrm{kW}$ & $€ 1050 / \mathrm{kW}(-58 \%)$ \\
Hydrogen gas grid (path 2) & Overall efficiency & $39 \cdot 9 \%$ & $41 \cdot 6 \%(+56 \%)$ \\
& Power-specific Capex & $€ 2500 / \mathrm{kW}$ & $€ 1096 / \mathrm{kW}(-58 \%)$ \\
Methane gas grid (path 3) & Overall efficiency & $26 \cdot 6 \%$ & $35 \cdot 3 \%(+66 \%)$ \\
& Power-specific Capex & $€ 2600 / \mathrm{kW}$ & $€ 1791 / \mathrm{kW}(-58 \%)$
\end{tabular}

Table 4. Assumptions for reference storage facilities at present and in 2030

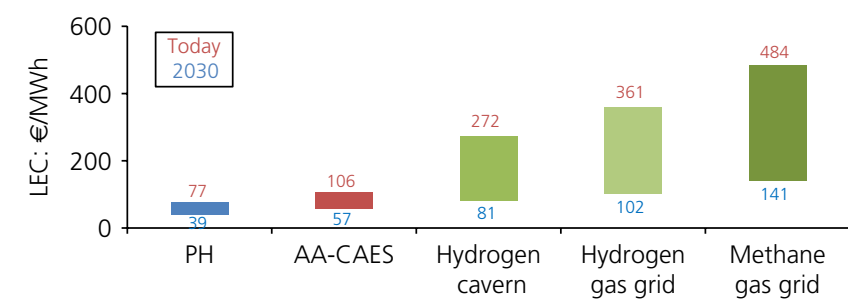

Figure 14. Development of LECs up to 2030 (STS)

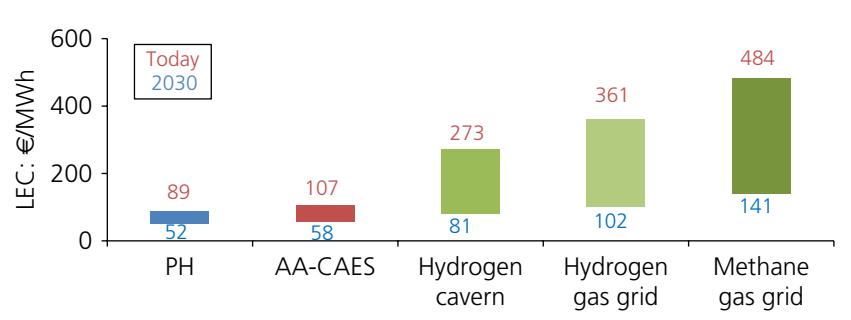

Figure 15. Development of LECs up to 2030 (MTS)

compressed air storage and $70 \%$ for hydrogen storage. Here too, there is no change in the ranking.

LTS. For long-term deployment, the picture changes. In this case, the reductions in LEC of $\mathrm{PH}$ and compressed air storage are only 10 and $20 \%$, respectively, and for hydrogen storage it is $70 \%$. As a result, hydrogen storage overtakes PH. On the basis of the assumptions made for 2030, both compressed air and hydrogen storage are more favourable than PH. Even for the costliest variant - that is, hydrogen storage (path 3 ) - the average, discounted costs of energy storage are only half those of $\mathrm{PH}$.

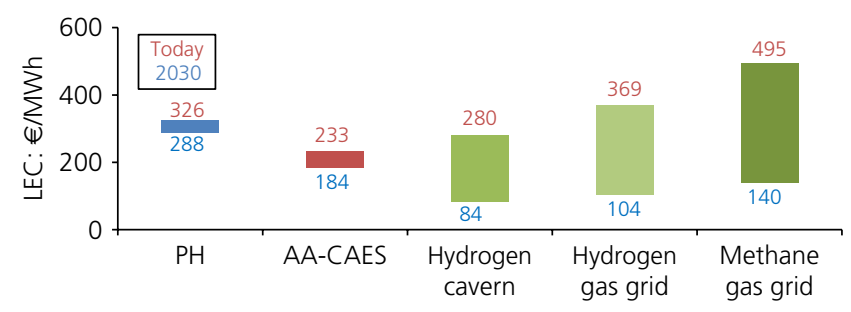

Figure 16. Development of LECs up to 2030 (LTS)

\section{Conclusion}

\subsection{Practical relevance and potential applications of} the work described

In the context of the German government's energy policy reorientation (Energiewende), there will be a growing expansion in the use of renewable energies. To ensure a reliable energy supply, in future energy storage will play a key role.

This paper is intended as an aid to (political) decisionmakers to answer the question of which utility-scale energy storage technology is to be favoured under economic aspects currently and in 2030. When doing the calculations, all substantive technical and economic parameters have been factored in. As an actual application, on the basis of these findings it is possible to focus on specific storage technologies of relevance for the respective deployment purpose. Furthermore, based on this analysis more advanced research programmes can be defined and initiated for particularly relevant technologies.

\subsection{Summary}

All three investigated storage systems are already technically feasible. When assessing the priorities investigated, at present the picture is as follows. In the deployment scenarios of STS and MTS, PH is the most cost-effective storage technology, 
closely followed by compressed air storage. In these deployment scenarios, hydrogen storage is not cost-competitive. Depending on storage path, its LECs are greater than the costs for $\mathrm{PH}$ and compressed air storage by a factor of 2-6. A critical factor for the poor performance of hydrogen stores is their very high specific power-dependent Capex in combination with their short service lives and low overall efficiencies. When deployed for LTS, though, the picture changes. For this dispatch scenario, $\mathrm{PH}$ is the costliest means of energy storage. Then the most favourable storage technology is compressed air, followed by hydrogen storage.

When considering the outlook for 2030, assumptions have been made as to how indicative values for the various storage systems could develop. The result of these investigations is that in 2030, too, for STS and MTS the most cost-favourable technology is PH followed by compressed air. Unlike today, for these dispatch scenarios, too, hydrogen storage reduces the gap to $\mathrm{PH}$ and compressed air. The picture changes for deployment as LTS. In this case, in 2030 for all storage-discharge paths hydrogen storage is clearly the most favourable technology.

In general, for hydrogen storage it may be concluded that at both the present day and in the future, path 1 with storage in caverns is the most favourable option when compared with path 2, storage of hydrogen in the natural gas grid, and with part 3 - that is, methanation of hydrogen and its storage as synthetic methane in the natural gas grid. The investigations were based on reconversion to electricity using FCs in all three paths. As noted, though, reconversion by means of conventional combined cycle gas turbine power plants is likewise an option. This would improve the economic performance of paths 2 and 3. If the further technological developments as described come to fruition, then in 2030 hydrogen storage will represent the most favourable of the storage technologies investigated in this programme for long-term energy storage.

\section{Acknowledgements}

This paper is based on the research project 'Erstellung eines Entwicklungskonzeptes Energiespeicher in Niedersachsen' (Elaboration of a development concept for energy storage in Lower Saxony) (Fichtner, 2014). This study was prepared by Fichtner $\mathrm{GmbH} \& \mathrm{Co}$. KG with Dr Florian Klumpp as project manager. Estimates of the potential and of the costs of underground storage of compressed air and hydrogen were undertaken by KBB Underground Technologies $\mathrm{GmbH}$, Hanover, Germany.

\section{REFERENCES}

CLCF (The Centre for Low Carbon Futures) (2013) Liquid Air in the Energy and Transport Systems - Opportunities for
Industry and Innovation in the UK. The Centre for Low Carbon Futures, York, UK.

Crotogino F (2010) Grid Scale Energy Storage Based on Pumped Hydro, Compressed Air and Hydrogen. KBB Underground Technologies GmbH, Hanover, Germany. Crotogino F (2011) Wasserstoffspeicherung im geologischen Untergrund - Stand der Technik und Potential. KBB Underground Technologies GmbH, Hannover, Germany (in German).

dena (Deutsche Energie-Agentur) (2010) Analyse der Notwendigkeit des Ausbaus von Pumpspeicherwerken und anderen Stromspeichern zur Integration der erneuerbaren Energien. Deutsche Energie-Agentur, Laufenburg, Germany (in German).

dena (2013) Power to Gas. Eine innovative Systemlösung auf dem Weg zur Marktreife. Deutsche Energie-Agentur, Berlin, Germany (in German).

DIN (Deutsches Institut für Normung e.V.) (2008) DIN 51624 : Kraftstoffe für Kraftfahrzeuge - Erdgas - Anforderungen und Prüfverfahren. Deutsches Institut für Normung e.V., Berlin, Germany (in German).

Donadei S and Zander-Schiebenhöfer D (2015) Bestimmung des Speicherpotenzials Erneuerbarer Energien in den Salzstrukturen Norddeutschlands: Vorstellung des Projektes InSpEE. KBB Underground Technologies GmbH, Hannover, Germany (in German).

Donadei S, Crotogino F, Acht A and Horvath PL (2013) Integration von Wind-Wasserstoff-Systemen in das Energiesystem Speicherung von Wasserstoff in Salzkavernen. KBB Underground Technologies GmbH, Hannover, Germany (in German).

DVGW (Deutscher Verein des Gas und Wasserfaches) (2013) Entwicklung zu modularen Konzepten zur Erzeugung, Speicherung und Einspeisung von Wasserstoff und Methan ins Erdgasnetz. Deutscher Verein des Gas und Wasserfaches, Bonn, Germany (in German). See http://www.dvgw-innovation.de/fileadmin/dvgw/angebote/ forschung/innovation/pdf/g1_07_10.pdf (accessed 06/03/2014).

EFZN (Energie-Forschungszentrum Niedersachsen) (2013) Studie Eignung von Speichertechnologien zum Erhalt der Systemsicherheit. Energie-Forschungszentrum Niedersachsen, Goslar, Germany (in German).

E.ON SE (2014) E. ON SE Power-to-Gas Pilot Unit in Falkenhagen. E.ON SE, Düsseldorf, Germany. See http:/l www.eon.com/en/media/news/press-releases/2014/9/1/eonpower-to-gas-pilot-unit-falkenhagen.html (accessed 09/01/2014).

Fichtner (2014) Erstellung eines Entwicklungskonzeptes Energiespeicher in Niedersachsen. Fichtner GmbH \& Co. KG, Stuttgart, Germany (in German). See http://www. energiespeicher-nds.de/fileadmin/Studien/Fichtner_Studie. PDF (accessed 05/09/2014). 
Genoese F (2013) Modellgestützte Bedarfs- und Wirtschaftlichkeitsanalyse von Energiespeichern zur Integration erneuerbarer Energien in Deutschland. KIT Scientific Publishing, Karlsruhe, Germany (in German). Hartmann N, Eltrop L, Bauer N et al. (2012)

Stromspeicherpotenziale für Deutschland. Institut für Energiewirtschaft und Rationelle Energieanwendung (IER), Institut für Strömungsmechanik und Hydraulische Strömungsmaschinen (IHS), Zentrum für Sonnenenergie- und Wasserstoff-Forschung BadenWürttemberg (ZSW), University of Stuttgart, Stuttgart, Germany (in German).

Konstantin P (2013) Praxisbuch Energiewirtschaft: Energieumwandlung, -transport und -beschaffung im liberalisierten Markt, vol. 3. Springer-Verlag GmbH, Berlin, Germany (in German).

Kost C, Mayer J, Thomsen J et al. (2013) Stromgestehungskosten Erneuerbare Energien. Fraunhofer-Institut für Solare Energiesysteme ISE, Freiburg, Germany (in German). Lehner M, Tichler R, Steinmüller H and Koppe M (2014) Power-to-Gas: Technology and Business Models. Springer International Publishing, Cham, Switzerland. Mahnke E and Mühlenhof J (2012) Agentur für erneuerbare Energien - Strom speichern. Agentur für Erneuerbare Energien e. V., Berlin, Germany (in German).

Rastler D, Akhil A, Gauntlett D and Cutter D (2012) Energy Storage System Costs 2011 Update - Executive Summary.
EPRI Electric Power Research Institute, Palo Alto, CA, USA.

RWE (2010) ADELE - Der adiabate Druckluftspeicher für die Elektrizitätsversorgung. RWE Power Aktiengesellschaft, Köln, Germany (in German).

Schapitz T (2014) Energiewirtschaftliche Bewertung großtechnischer Stromspeichertechnologien in unterschiedlichen Einsatzszenarien. Master thesis, Institut für Energiewirtschaft und Rationelle Energieanwendung (IER), University of Stuttgart, Stuttgart, Germany (in German).

Simona J, Ferriza AM and Correasa LC (2015)

HyUnder - Hydrogen Underground Storage at Large Scale: Case Study Spain. 9th International Renewable Energy Storage Conference (IRES) 2015. Energy Procedia. vol. 73, pp. 136-144. Elsevier Ltd., Amsterdam, Netherlands.

Wissel S, Rath-Nagel S, Blesl M et al. (2008) Stromerzeugungskosten im Vergleich. Institut für Energiewirtschaft und Rationelle Energieanwendung (IER), University of Stuttgart, Stuttgart, Germany (in German).

Wissel S, Fahl U, Blesl M et al. (2010) Erzeugungskosten zur Bereitstellung elektrischer Energie von Kraftwerksoptionen in 2015. Institut für Energiewirtschaft und Rationelle Energieanwendung (IER), University of Stuttgart, Stuttgart, Germany (in German).

\section{HOW CAN YOU CONTRIBUTE?}

To discuss this paper, please email up to 500 words to the editor at journals@ice.org.uk. Your contribution will be forwarded to the author(s) for a reply and, if considered appropriate by the editorial board, it will be published as discussion in a future issue of the journal.

Proceedings journals rely entirely on contributions from the civil engineering profession (and allied disciplines). Information about how to submit your paper online is available at www.icevirtuallibrary.com/page/authors, where you will also find detailed author guidelines. 